NEWS

\title{
Avian influenza aided readiness for swine flu
}

\section{Despite gains from threat of bird flu, pandemic preparedness is patchy.}

With the World Health Organization discussing whether to declare, as Nature went to press, that a swine influenza pandemic has arrived, doctors, scientists and government officials say the enormous preparedness efforts of recent years have aided the world's response to the virus.

"Clearly, the global preparedness for dealing with an influenza outbreak is much better now than it was five or six years ago," says virologist Malik Peiris of the University of Hong Kong.

But there have been some hiccups, due largely to the mismatch between the pandemic scenarios envisaged and the one that has arrived. Most nations had prepared for a pandemic sparked by the deadly A(H5N1) avian influenza virus, which kills up to $60 \%$ of those infected, but the $\mathrm{A}(\mathrm{H} 1 \mathrm{~N} 1)$ swine flu virus epidemic has been much less severe so far.

"Many nations built their plans around the idea that a pandemic strain would evolve in southeast Asia, that we would recognize it early, and that we would be able to contain it," says Eric Toner, a physician and preparedness analyst with the University of Pittsburgh Medical Center's Center for Biosecurity in Pennsylvania. "None of that turned out to be true."

Global pandemic planning efforts were ramped up after severe acute respiratory syndrome (SARS) swept through Asia in 2003,
"The idea that one could trap it at the early stages was certainly not successful." and the deadly H5N1 strain emerged in the same year. Local, national and international entities involved in flu response are now better coordinated, observers say.

That was evident with regard to the current situation, as officials - for instance, at the US Centers for Disease Control and Prevention in Atlanta, Georgia - delivered open and consistent public messages about the seriousness and uncertainty of swine flu infections, says Georges Benjamin, executive

\section{PREPAREDNESS BY THE NUMBERS}

Number of European countries surveyed in 2005 that had a pandemic flu plan: 21 of $\mathbf{2 9}$ Average completeness of the plans ${ }^{\star}: 54 \%$

Number of Latin American countries surveyed in 2007 that had a flu plan: $\mathbf{1 5}$ of $\mathbf{1 7}$ Average completeness: $\mathbf{4 8 \%}$

Number of Asian countries surveyed in 2005 that had a flu plan: 6 of 9 Average completeness: Not available

Number of African countries surveyed in 2007 that had a flu plan: 35 of 53 Average completeness: $36 \%$

Doses of $\mathrm{A}\left(\mathrm{H}_{1} \mathrm{~N}_{1}\right)$ vaccines ordered by: United States: $\mathbf{4 0}$ million

United Kingdom: 90 million

France: $\mathbf{5 0}$ million

Belgium: 12.6 million

Finland: 5.3 million

Australia: 10 million

Per cent of the population covered by government antiviral stockpiles in: United States: $\mathbf{2 5 \%}$

United Kingdom: $50 \%$

Hong Kong: $\mathbf{2 8 5} \%$

Thailand: $5 \%$

All nations outside the nine currently capable of producing a pandemic vaccine: $\mathbf{1 \%}$

\footnotetext{
*Based on the World Health Organization checklist for influenza epidemic preparedness.
}

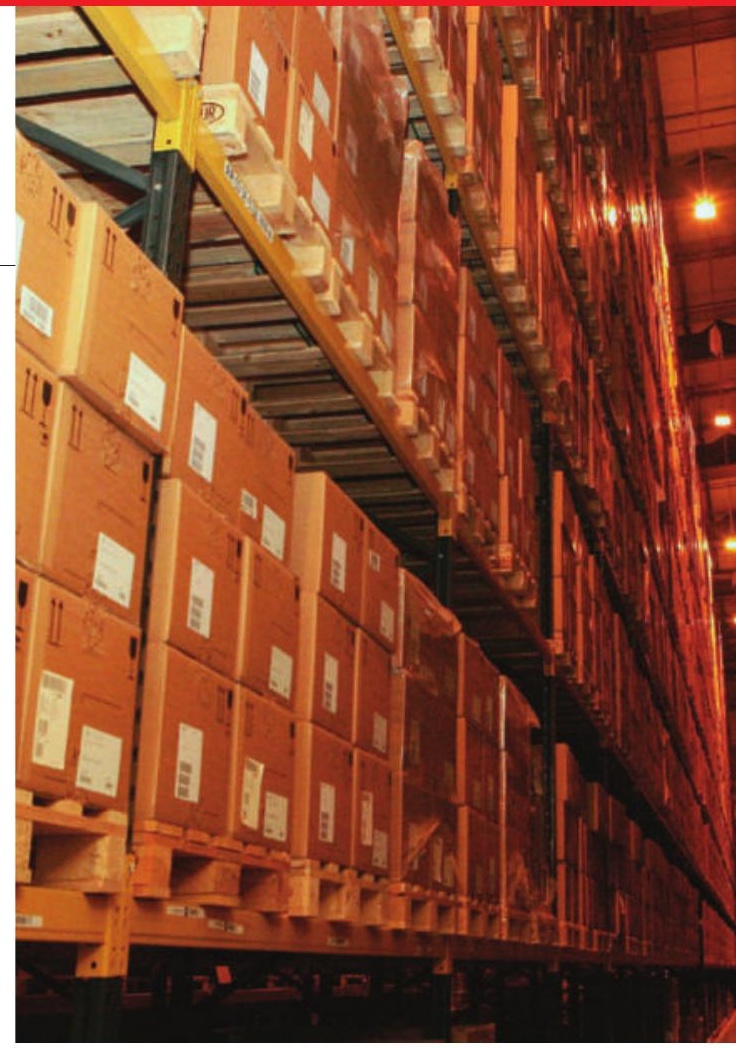

director of the American Public Health Association in Washington DC. That's in contrast to 2001, when some conflicting messages were delivered during the anthrax attacks.

In some countries, pandemic planning has led to stockpiled antiviral medication (see 'Preparedness by the numbers') being distributed to treat people with swine flu and their contacts. And the boost in research spending on epidemiological modelling and laboratory studies has enabled scientists to understand the H1N1 virus in record time, prepare to manufacture more vaccine faster, make more informed decisions on how to intervene in the virus's spread, and understand and share information on its genetic characteristics.

"We got an extraordinary laboratory understanding of this virus in a very short period of time, and that is the scientific 'wow' of what really happened in this outbreak," says Benjamin.

But the divergence between the anticipated pandemic and the one that has actually arrived has caused some glitches. For instance, the swine flu virus was not detected in time to contain it, as had been envisaged in some scenarios involving avian flu. "By the time the surveillance systems picked [the virus] up, it was already spreading way out of control, so the idea that one could trap it at the early stages was certainly not successful," says Peiris.

As swine flu began to spread throughout North America, which had hoped to have weeks of warning before a virus arrived from Asia, officials were initially confused about how to implement response plans. For instance, swine flu symptoms were milder and less severe than anticipated - impossible to distinguish from seasonal flu — and hospitals and health departments were swamped with people seeking tests for swine flu. A report issued on 4 June 
